\title{
REMOVING THE WALLS AND TEXTBOOK FROM THE CLASSROOM
}

\section{A case study of a creative entrepreneurship class of multinational students in South Korea}

\author{
Zen Parry \\ RMIT University, Australia \\ zenparry@gmail.com \\ Craig Baird \\ Curtin University \\ Perth, Australia \\ c.baird@curtin.edu.au
}

\begin{abstract}
Introducing creative elements into the syllabus and pedagogy of an Entrepreneurship class in a business school can be a risky endeavour for an educator and students alike. Populating the class with students from traditionally risk-averse cultures provides opportunities for everyone involved. Identifying the core behavioural issues for students in this learning experience brought creativity and entrepreneurship together in the academic environment. Emergent was a joint learning workshop using Skype, involving a book author, a multilingual multicultural class in South Korea and a culturally homogenous class in Indonesia. Along the way, the walls of the classroom were removed and the covers from the book disappeared. At the end of the journey, a new paradigm had emerged, driven and defined by the students that want to be the Entrepreneurs of their own worlds. This is the story of one creative entrepreneurship class of multinational students in South Korea.
\end{abstract}

\section{Keywords}

Collaborative learning, synchronous online activities, Skype, transnational and multinational teaching

\section{Introduction}

Today in the business school classroom, it is still common to see familiar textbooks from a decade ago, along with teacher-focused transmissive teaching styles with students seated, books open, waiting for the knowledge to arrive. The advent of new communication technologies has brought with it teaching and learning opportunities not necessitating a teacher being physically present in the classroom (Wallhaus, 2000). In the teaching world of Entrepreneurship, classroom and book based knowledge delivery is but one mode of learning. The current generation of students now choose to adopt eLearning methods for their flexibility with the time and place of learning, over a more conservative and traditional style classroom (Walters-Cappola, 2002). One of the keys to 
making informed choices about the mode and types of learning experiences in eLearning situations is having timely and appropriate feedback (Kemshal-Bell, 2001; Shepherd, 2000). Student use of eLearning methods is shaped by the immediacy and effectiveness of information they obtain using tools such as social media that can deliver instant feedback concerning their performance. You only have to casually observe the students' use of Facebook, Twitter, Daum, Naver, QQ and Google as well as phone applications that allow messaging, to recognize this pattern of behavior being echoed frequently. In preparing an approach to eLearning for entrepreneurship education students, it became evident that there was a gap between the environment in the business school classroom and the reality that entrepreneurs face when they enter the professional world beyond to launch their dreams. Another key factor considered was that in this study, computer-mediated communication in the eLearning situation was influenced by the student participants being from multiple cultural and linguistic backgrounds, having English as an additional language (Simpson, 2005). This added a layer of complexity given that much of what takes place using social media is concerned with "getting acquainted" (Jenks, 2009) with others and this process is part of establishing interactive learning groups in eLearning settings.

The purpose of this paper is to outline the development of the pedagogy, materials and delivery methods for teaching entrepreneurship for undergraduate students using innovative eLearning technologies to facilitate authentic entrepreneurial experiences at an international business school in South Korea. Through the pedagogical development process, three questions emerged:

1. If the students in the Entrepreneurship classroom originate from risk-averse cultures, what can the educator do to ensure a risk-friendly entrepreneurial mindset?

2. If the students in the Entrepreneurship classroom are multilingual, multinational and digitally savvy, then what can the educator do to facilitate their creativity?

3. Can the educator reduce the gap between being a student inside the classroom and becoming the Entrepreneur working in the outside world?

Learning in eLearning situations is shaped by the relationship between the linguistic and social interaction dimensions of language (Ellis, 2008) which facilitate student transfer of knowledge from inside the virtual classroom to the world of professional practice. In this study, the dynamic synchronous communication opportunities provided by the online tools used required students to rapidly adapt to the language, cultural characteristics, rules, norms and expectations of other students in a fluid virtual classroom (Jenks, 2009).

\section{Background of SolBridge International School of Business}

Located in Daejeon, South Korea, the school was founded in 2007 and offers an undergraduate degree in Business Administration and a two year Masters in Business Administration. All classes are delivered in English by Faculty comprising of both native and non-native English speakers. In 2011, the student population exceeded 500, with foreign students representing 36 countries accounting for $80 \%$ of the overall population, while enrolment for South Korean students is capped at $20 \%$. The faculty is equally diverse with scholars drawn from some of the best institutions in the world, representing more than twenty countries, with professional experiences from numerous emerging economies to reflect their international knowledge and Asian expertise.

The teaching style and pedagogy emphasised at SolBridge is interaction and student engagement, based on the American Liberal Arts model. Students are encouraged to be active and vocal in all classes which differs from the educational experiences that many of the students have had prior to 
studying at SolBridge. In numerous Asian environments, students are passive and very subdued in class, relying on memorisation for coursework and exams (Lui \& Gao, 2010; Than, 2011). Typically these students exhibit compliance and deference towards the educator in the classroom setting (Hebblethwaite, 2010), with an intense focus on protecting their cumulative Grade Point Average (GPA) scores per semester.

\section{The pedagogy and syllabus of Entrepreneurship at SolBridge}

An elective third year undergraduate subject offered in the Entrepreneurship stream is "Entrepreneurship in Emerging Markets." Its underlying principle is an entrepreneurial mindset that 'you can start a company without any money or a business plan in your home country.' The values emphasised in the class were Leadership, Teamwork, Communication and Management. Content delivered in the class varied from digital media available online, to real world experiences relayed by speakers and educators, or instant 'iPhone Google' type searches while researching a topic or statistic, as well as presenting traditional theory using PowerPoint techniques. Contact time was two ninety-minute sessions each week with group-managed and scheduled team meetings outside of the regular class timetable.

This Entrepreneurship class at SolBridge represented 12 different nationalities (Indian, Chinese, Thai, Vietnamese, Russian, Guinea, Indonesian, Australian, Kazakhstan, Taiwanese/Malaysian, Korean and Mongolian) amongst 29 students that included 10 exchange students and one full-time educator. The learning support book (LSB) assigned to the class comes from the Microsoft Leadership series, titled Young World Rising by Rob Salkowitz, and noted as not being a traditional textbook for academia. This book offers the premise that 'youth, technology and entrepreneurship are changing the world from the bottom up' and includes multiple case studies of peer group entrepreneurs that are similar to the student profiles in the South Korean class. Leading this class case study learning exercise was educator Zen Parry, one of the authors of this paper, who is a veteran of the corporate world and has worked internationally in numerous countries and cultures for more than thirty years prior to joining academia in 2009.

For the fourteen-week Spring semester of 2011, Parry, in her inaugural teaching assignment, introduced the class to a suite of learning activities, tools and processes with a radically modified syllabus aimed to reflect the kinds of practices and experiences that student might encounter in their professional careers. Some of the introduced elements were designed to bridge the gap between being a student and gaining hands-on experience as an Entrepreneur with the professional world that they will be entering during the next 12 months. Other elements were specifically designed to expand the academic experience of the students beyond the classroom and the covers of the LSB. Similar elements were also introduced into a class being taught by the same educator, 'Introduction to Entrepreneurship' with equivalent successful results and feedback. This class also represented the cultural diversity that SolBridge is known for. The findings for this class are not addressed in this paper. A list of the major elements introduced into the syllabus during the semester included the following:

1. A weekly classroom format similar to a corporate business meeting for delivering information and teaching points, including a non-classroom style seating, a published agenda for the meeting, a (student) designated moderator and presentations of updated information relating to prioritised issues.

2. Exams were replaced by ' 360 degree Performance Reviews'. Homework deliverables were team-based and driven by deadlines, often consisting of business document formats such as proposals, plans and professional quality communications in email. 
3. Feedback was to be given to individual students twice during the semester, through a formal appointment and meeting, to identify objectives together, create a verbal contract for performance improvement, and to set specific targets and goals to achieve.

4. A roster of ten invited entrepreneurs to speak to the class about their experiences in starting their business. After each presentation, the students had to submit a feedback email to the Lecturer discussing the content and the quality of the presentation.

5. A day-long field trip to visit an Incubator Centre that is a flagship for government initiatives to support students as Entrepreneurs in South Korea.

6. An opportunity to start a cooperative based companyi in real-time as students was created. All of the key structure and organisation decisions including the ownership model and country of legal registration were researched and decided by the students.

7. All activities were team based with a leader and team roles, similar to a traditional company structure with divisions and function-based groups such as Finance, Marketing, Human Resource Management, Operations and CEO leadership. Students can be fired from their role for non-performance, but remain in the class, at the discretion of the majority vote of the students.

8. A Skype 'one-to-one' based workshop with the author of the book identified to support the class.

9. A Skype 'multi-channel' based joint learning workshop with a compatible class offshore to South Korea.

\section{Challenges - Every class session seemed to bring a new one!}

There were several challenges identified before, during and after implementing each of these elements. The overall success of the class hinged on the ability of the students to work together and form teams. To support that potential success, one rule was endorsed when creating the teams: there must not be one dominant language (non-English) in the group and all members must use English as the common language. Graddol (2006) notes that there are more people using English as their first language than those who speak English as their first language. Despite record setting enrolment numbers for this class, five students of the initial intake withdrew in the first week once the concept of using Performance Reviews as the exam for the class was understood. It appeared to be that if they could not memorise for an exam to guarantee their scores, then they did not want to participate.

Similar withdrawal numbers through the 'drop' process were noted in the parallel class not discussed in this paper. Student enrolment for the 'Introduction to Entrepreneurship' class dropped from 35 to 21 in the second week. After this point, enrolment numbers remained stable for the remaining weeks. In both classes, the initial student enrolment numbers were record setting. The confirmed enrolment numbers for both classes still exceed previous enrolment levels over the previous three years by a factor of eight. This increase in enrolment is attributed to the addition of the creative elements in the syllabus.

In the early weeks of the semester, one key trait emerged very quickly amongst the students: at this point in their academic careers, students originating from Asia were not familiar with general teamwork concepts such as sharing of information, consistent communication and division of 
work, punctuality, and valuing joint contributions. For most members of this class, their academic experiences to date had been based on individual effort in isolation in a highly competitive pressurised environment. Generally, the students did not know how to collaborate in any form, nor knew how to become organised to commence collaboration. For many students, 'teamwork' was a new concept for them to learn.

Other traits emerged simultaneously: the students all use technology to communicate with each other, but depending on the culture of origin, the technology might not transfer easily across cultural lines. For example, Chinese students had not seen or used Facebook before arriving in South Korea as Facebook is banned in China. South Koreans have multiple choices for this type of platform but are often walled off from each other depending on their provider, requiring multiple memberships and logins to remain accessible to other users. Many countries also have unique messaging platforms that are not always language character compatible to other nationalities and do not perform well over such geographic transmission distances.

Even though cell phones are ubiquitous, limits in communications between classmates were quickly identified due to the usage rules for individual cell phone plans, the number of characters in a single message also created limits, as did how the student used the device and when it was turned on or off. Despite having unlimited access to technology and devices and a high level of comfort and reliance in using the technology and devices, the students still struggled with getting everyone to the same place at the same time to have a weekly team meeting. The biggest challenges came when students were asked to step outside of their comfort zone and do simple actions such as introduce themselves to a stranger from another culture. This is of course common to most in-class learning situations but in this undertaking, transferred to the mobile technologies used for communication and information sharing.

\section{Results - Pick one issue and solve it}

After lengthy discussions in class, one common platform was identified: Skype. Many studies have already shown that as a social media tool Skype is widely used by students to connect with family and friends (Woo, 2006). This made Skype a useful common tool for communication.

For the current generation of students participating in this business program, their daily experience with working virtually is more frequent, more inclusive and more social than the educator might realise. However, the frequency of those interactions does not guarantee quality exchanges or success towards a goal. After receiving feedback and directly observing the dynamics of the situation, the educator identified one fundamental issue that needed to be addressed in this complex paradigm: the students did not know how to collaborate.

\section{Identifying the technology of choice for collaboration}

After extensive research by the students, a proposal was made to the educator to introduce the Skype multi-channel video conferencing technology, referred to as Skype, as a means for class communication. Skype is a simple, relatively low-cost method for creating joint learning experiences that can easily mimic an equivalent professional situation that any business graduates will encounter. One of the key features of this version of Skype is being able to transmit up to 10 different participants on the screen at the same time. What the students brought to this experience was a set of expectations and assumptions that exceed the walls of the classroom and the covers on the book assigned to that class. 
The crowning experience and event in this class was to create a joint learning experience that involved everyone in the multicultural entrepreneurship class in South Korea, Rob Salkowitz in the USA as the author of the chosen course text book, Young World Rising, and a compatible but culturally homogenous entrepreneurship class from the Universitas Semarang in Indonesia.

\section{Context of the Joint Learning Workshop}

The reasons for taking part in the joint learning workshop were varied: Parry felt that the students in South Korea would benefit from validating their opinions with other students in another country in real-time while the author, Rob Salkowitz, was seeking feedback and opinions on his latest essay titled "The Enemies of Entrepreneurship" from a new potential market in Indonesia and to also reinforce his relationships with the South Korean class that had been established with an earlier Skype 'one-to-one' workshop. Further, the 62 students in Indonesia wanted to validate their opinions with students from other countries as well. It was through a general discussion in class that the concept for a video conferencing workshop was identified. The primary connections were made between the six Indonesian students on exchange at SolBridge in South Korea with one of their counterparts at Universitas Semarang in Indonesia.

The managing educators from South Korea and Indonesia agreed that the format that could provide the most participation from each of the three parties was an online, group video conferencing workshop event. The workshop was designed to give the students a first-hand experience in comparing and contrasting opinions on shared topics, to create interaction between all participants, to learn from each type of participant (collective, cultural and individuals) and to work together while being managed through a designated moderator.

The key objective of the workshop was to creatively increase learning for all participants by introducing familiar social media technology into multi-location learning sites. The secondary objectives of this workshop were to:

- 'Remove the walls' of a classroom and involve other suitable groups to facilitate new relationships for learning from each other;

- 'Remove the textbook' from the classroom by involving the author of the textbook personally for real-time commentary, interaction and engagement on the work that he presents in his book; and,

- Discuss an unusual perspective associated with entrepreneurship, that is, "The Enemies of Entrepreneurship" and gain cultural opinions on each of the six themes contained within that document provided by Rob Salkowitz.

\section{Methodology of the Joint Learning Workshop}

All participation in the workshop at all phases of development and on the day of the event was voluntary but managed as part of the syllabus for the class for the semester. The event did not require special permissions or ethical approval to participate. Each of the managing educators in Indonesia and South Korea were responsible for identifying the respective teams, supporting their preparation, providing the content for preparation, and getting the environment ready for the event. 
Both educators were active in observing the development phase of the event, the rehearsal prior to the event, the activity on the day of the event, and in post-event interviews, feedback and surveys. A short survey was designed to capture feedback based on the students' perceptions about the value of the experience and if the experience increased their individual learning. Then, if positive, they were invited to explain how their learning changed. The survey was distributed amongst the student participants in South Korea and in Indonesia. The response rate was $45 \%$ with the 55\% non-response rate attributed to student mobility during the summer holiday season.

The selection and evaluation of Skype as the technology platform was based on the participants' choice and familiarity with the technology. All students in the class in South Korea were familiar with Skype in the one-to-one format. The same students had also participated in a free trial of the group conferencing version of Skype through the study program syllabus and declared it 'very user friendly and able to enhance their collaboration experiences.' The same class also conducted a one-to-one Skype workshop with Rob Salkowitz at an earlier date in the semester and declared that experience as extremely valuable for their learning. The Indonesian class was also familiar with the Skype one-to-one format but did not participate in a trial version of the group conferencing version prior to the workshop event. Salkowitz had had multiple experiences on various social media platforms including Skype, Twitter, Facebook, blogging, v-logging, being interviewed for broadcast television and creating podcasts.

Skype offered multiple advantages for achieving the objectives of the project. These advantages included:

1. With the modest monthly subscription cost being carried by SolBridge, all participants could join the group call at no cost.

2. Each environment (classrooms and the professional office for Rob Salkowitz) already had the appropriate infrastructure with fibre optic networks to carry the transmissions, including video images, to make the group call possible. No other special technologies were required to make the group call happen. Other support elements available in the classrooms included a projector and screen to project the images on to for all participants to see, a computer console for managing the technology platform, and a microphone and speakers for input and output of audio.

3. Other technology options are available through Skype include text messaging and sending documents in real-time. The messaging function can mimic a micro-blogging function that can be seen on the screen for all participants to read.

4. The use of Skype mimics current global business processes through collaboration exercises, team based video-conferencing, and for making online presentations over borders and distances.

\section{Observations from the Joint Learning Workshop}

Often in multicultural settings, different nationalities can naturally dominate depending on their social frameworks, social development practices, lifestyle and overall maturity levels prior to participating in this type of learning experience. Based on the South Korean educators' experiences in many Asian based environments, gender can play a significant role, with a tendency for the male participants to speak up before females. Overall interaction can be quite passive, subtle and muted when compared to an equivalent western environment. 
As noted by Hofstede (2006), another key factor is the Power Distance Ratio between students and professors or other persons in authority, with the understanding that in Asian environments, there is automatic deference by the student to persons in positions of authority. This point is mentioned because the class in South Korea is taught in a seminar-based style, with first names only, including when addressing the educator. In this format, the students have an equal voice with the educator to minimize or completely eliminate the power distance ratio. The class in Indonesia is a more traditional Asian academic environment where the educator has full authority through her title and is deferred to by the students accordingly.

A cultural trait often noted in many Asian based environments is the reluctance of an individual to perform public speaking duties in any format. When working in a non-native language, many Asian students will express a general fear about the quality of their spoken English language, as well as the general fear of being in front of an audience, especially an audience of their peers. Some of the observations made about the workshop event are as follows:

1. The lack of gender domination was evident for the class in South Korea with all members of the class being vocal and active in their conversations during the event and between speakers. The workshop experience provided an equal opportunity for representatives in each of the six designated teams from the class in South Korea to be nominated to present their viewpoint. One particular presentation was made by a female student in her first ever public speaking engagement that was both extremely competent and articulate and noted by all participants, including Rob Salkowitz. For the class in Indonesia, there was a smaller representation but equal presentations by female and male students. Generally, the audience in Indonesia was passive and quiet when speakers were at the microphone that was shared by the class when communicating with others online.

2. The lack of the power distance ratio was evident in the class in South Korea, as all representatives stepped up to the microphone without hesitation, taking their cue from the moderator for the event who was also a peer. The power distance ratio was evident in the class in Indonesia, as students actively took their cue to speak and come to the microphone from their educator. The class in South Korea demonstrated a level of familiarity with Rob Salkowitz that eliminated the power distance ratio. The class in Indonesia remained deferential to Salkowitz, for a number of reasons that are difficult to identify.

3. The class in South Korea was familiar and comfortable with the format for public speaking and demonstrated a level of professionalism that mimicked young business professionals. They had rehearsed their presentations to fit in the time requirements of the theme, and read from scripts. Two confident speakers dominated the class in Indonesia, who read from scripted notes and also gave informal opinions through extemporaneous speaking. Both classes were serious in tone during their presentations and many nonpresenters had prepared written questions. The question time was cut short due to overrun of some of the presentations during the event. What was noticed amongst participants in both classes was the change in personalities from the informal atmosphere before the event commenced when introductions were being made to how serious the personalities became once the event had commenced and was being actively managed and transmitted.

\section{Feedback on the Entrepreneurship class in South Korea}

Overall the South Korean Entrepreneurship class has been successful due to the new elements introduced into the syllabus, as validated through the student evaluations. The evaluations 
identified consistent experiences that the students regarded as being extremely valuable for their learning experience and also towards their professional development. The general comment in the evaluations was that the class was creative, entrepreneurial and non-traditional, with the expressed implication that the class is worth the risk to their GPA scores. There were no recorded formal protests or complaints lodged by students to challenge their final grades, which was equally unusual in this Asian academic environment. Four students stated to the teaching assistant, that although they knew they would receive comparatively very low grades, this class delivered the most value and learning for the semester and was their favourite class.

Individual elements introduced into the syllabus were also evaluated critically through the student evaluation process. The invited guest speakers demonstrated to the students the value of gaining highly developed presentation skills. The students also developed their critical writing skills with each exercise to give feedback on the presentations. Running class sessions as a business meeting immediately invoked a different sense of professionalism and 'business' that the students responded to in an extremely positive way, through their input and participation. One business meeting style class hosted a group of 30 visiting students from a partner institution with SolBridge. The visiting group gave positive feedback about the format and experience of witnessing the class. The feedback and response from this class was verbal and relayed through the staff member hosting the group. The comments were positive and expressed surprise at how unusual the class was in the format and content and also in the behavior of the students participating.

Founding a company together, then managing the company through the classroom business meetings also added a sense of professionalism and authenticity that was not being experienced in other classes. Students also had an opportunity to witness what a start-up company looks like and to gain comments from entrepreneurs by visiting an incubator center on the field trip. Students saw first-hand that a startup can be extremely humble, and sometimes does not have much furniture, but as long as the passion is there, the idea can evolve.

The Performance Review process that substituted mid-term and final exams provided some of the most important insights and comments from the students overall and identified how their sense of professionalism was being developed. Many students commented that this process allowed them to make important statements and judgments that culturally they could not do so easily as individuals. An example might be that a team member can perform well in the classroom but be completely ineffective, disruptive, unproductive and unaccountable outside of the classroom. The review process allowed other students to judge that team member accordingly, and make that student accountable for their behavior and actions through the Performance Review scores.

One new element that was introduced to the syllabus that was extremely controversial in the early weeks of the semester was for the educator to be able to 'fire' someone from their team role and in some cases, from the team as well, with an option to 'drop the class academically' or stay in the class and undertake another function role or find another team that they can join. One student opted to withdraw from the class academically on her own volition. Another student was given an administrative withdrawal due to his controversial personality and performance, as identified through student feedback from $98 \%$ of the class. Generally though, after becoming familiar with this concept of management, and experiencing 'being fired' many students expressed how much they had learned as a result of the experience.

Some of the outstanding performances through the semester, both professionally and academically, came from students that were emerging from some of the more traditional education experiences known in this paradigm. Many of these students had never spoken in a class before, let alone spoken with a foreign educator, in front of other foreigners or even across technology to students in another country. As commented upon by their peers, many students were 'completely different in personality' in the Entrepreneurs' class when compared to their behaviour in the other, more traditional business classes. 
The strongest comment made by students in the class is they had never met an author of a book that they used in a classroom before. This experience had a profound and positive impact on their opinions about the content and their relationship to that particular book. The same students also expressed how equally strong the impact of participating in the workshop event with the author has been in developing their confidence and ability to interact with others. The students also expressed equally strong support for the Joint Learning Workshop experience and now believe that they have the confidence to create and manage a similar joint learning workshop event through other environments.

\section{Feedback on the Joint Learning Workshop}

In terms of the Joint Learning Workshop, the consistent opinion from all participating students and educators from South Korea and from Indonesia is that one workshop together in a semester is not enough. After the joint learning workshop event, an informal survey was conducted and feedback was solicited to establish the value of the exercise. The general comment was that the experience was valuable on three levels:

1. The students from the class in South Korea had learned how to organise, manage and conduct a workshop involving other participants in other countries. From this experience, their confidence was significant that they could conduct the same event in a professional environment to facilitate collaboration meetings, or video conferencing activities relating to a project.

2. The general consensus was that the workshop provided a real-time format that expanded the learning of all participants in two ways - using technology to create such an event, and then analyzing the content presented through the workshop format: that is, opinions from nationals of other countries.

3. Both classes in the workshop had different educational philosophies:

- The class in South Korea was based on being an entrepreneur and starting a company with no money and no business plan.

- The class in Indonesia was focused on making a profit and starting a business from a business plan.

This intersection of conflicting philosophies provided many interesting points of discussion that allowed respective students to voice their personal opinions and ideals strongly with little risk. Prior to the day of the event, many of the students in the Indonesian class were heard to comment in Bahasa Indonesian to their countrymen in the South Korean class that they were highly sceptical of the value of the class content and experience in South Korea. The conclusion at the end of the workshop was that many students from the Indonesian class were less skeptical about the approach and mindset being undertaken by the students in the South Korean class.

Many students from the class in South Korea expressed their interest in doing more events similar to the workshop, to facilitate learning and establish new relationships with students that are not in their immediate environments in South Korea. The Indonesian and Russian speaking exchange students that were part of the class in South Korea all gave commitments to establish the workshop format in their respective home institutions, so that subsequent events can be conducted during the following semester. 
The survey results also identified what the students regarded as the change in their learning experience. The majority of students mentioned that being able to interact and engage with the book author, and other students similar to themselves whom they did not know, truly expanded their learning experience. Other comments made in the survey were suggestions about the timings of the event and how to incorporate more participation from the different groups, so that more information could be exchanged. Every suggestion had merit and will be incorporated in the next series of Skype multi-channel joint learning workshops. Some examples of these suggestions included having non-presenting team members blogging or microblogging in real-time as the event is happening; incorporating other uses of images to create a dynamic record of the event that can be posted online; introducing support pages through the Biz-Bridge company blog linked to Facebook; and introducing an entrepreneur (perhaps a case study from the book Young World Rising) to add his/her voice to the participants of students, educators and author.

\section{Emergent from this eLearning entrepreneurship undertaking}

Within weeks of the Joint Learning Workshop event, Zen Parry received requests from Faculty in other non-Korean institutions, requesting to collaborate and conduct similar workshops. Many of these requests came from the exchange students returning to their home campus and sharing their vivid experiences in Parry's entrepreneurship classes while at SolBridge.

As a result of the feedback and evaluations from the 'Entrepreneurship in Emerging Markets' class and a similar format class taught as 'Introduction to Entrepreneurship', students have expressed interest at record levels for SolBridge for any class in entrepreneurship including the types of creative elements discussed in this paper. The next class planned to incorporate similar elements is 'New Ventures in Entrepreneurship' which has as its focus social entrepreneurship and the principles of social business as exemplified by Dr. Mohammad Yunus.

One set of relationships identified for development includes co-designing course content for a Social Entrepreneurship class for senior undergraduates and MBA students in South Korea, Indonesia and Australia. Examples of some of the new elements being incorporated into course syllabi at the time of writing this paper include:

1. A collaboration work-shop event using live-streaming on the internet (through Tedx.com) involving multiple student groups, Non Government Organizations, Bloggers and Writers from Japan, Singapore, Indonesia, Australia, the USA and multiple universities from South Korea;

2. Case studies to include real-time discussions with Entrepreneurs working in aligned sectors and the students posting their researched company profiles online at Wikipedia (http://www.wikipedia.com); and.

3. The real-time monitoring of a live project currently in action in an appropriate geographic area such as a project in Japan as it recovers from the triple tragedy experienced in March 2011.

Findings from this learning activity have led to a collaborative undertaking with faculty at Curtin University in Western Australia where the methods developed are being implemented into the oneto-one and one-to-many student learning support services in the Curtin Business School. This international collaboration is planned to include interactive Skype learning sessions involving students in Australia directly with those in South Korea and others who participated in the study reported here. 
All these experiences and events will also be posted to the blog site founded in late 2011 as a cooperative company by the entrepreneurship class in South Korea. The intention is that recording these experiences and events on this student managed website will create a central point for collaboration, continuity and community in this creative approach to developing students' entrepreneurial mindset.

\section{Conclusion}

By adding new creative elements to the syllabus for the 'Entrepreneurship in Emerging Markets' class, students in that class were able to experience real-time events that impacted their learning experience in entrepreneurship and as potential entrepreneurs about to enter the professional business world. Through new creative elements being incorporated into a syllabus and delivered with a suitable pedagogy, it is evident that students from risk-averse cultures can develop an appropriate mindset and a comfort level with events usually associated with entrepreneurial activities. By removing the mystique around certain entrepreneurial activities and creating realtime opportunities to experience such activities, entrepreneurship has been presented as a set of accessible activities that are within the reach of the undergraduate student. Introducing a simple process for collaboration based on a technology that supports collaboration also extends the student experience beyond the classroom walls and the covers of the textbook. The gap between the student sitting in the classroom and that student becoming an Entrepreneur working in the outside world can be minimised very successfully through introducing creative behaviour-based elements into an academic syllabus.

\section{References}

Ellis, N. (2008). The dynamics of second language emergence: cycles of language use, language change and language acquisition Modern Language journal, 92, 232-249.

Graddol, D. (2006). English Nest: Why Global English may mean the end of 'English as a foreign language.' London: British Council.

Hebblethwaite, D. (2010). Effective teaching strategies in the culturally diverse classroom. Interdisciplinary Journal of Contemporary Research In Business, 2(8), 23-28.

Hofstede, G. (2006). What did GLOBE really measure? Researchers' minds versus respondents' minds. Journal of International Business Studies, 37(6), 882-896.

Jenks, C. (2009). Getting acquainted in Skypecasts: Aspects of social organization in online chat rooms. International Journal of Applied Linguistics, 19(1), 26.

Kemshal-Bell, G. (2001). The online teacher, Final report prepared for the Project Steering COmmittee of the VET teacher and On-line Learning Project: ITAM, ESD, TAFENSW.

Liu, S., \& Gao,Y. (2011). Teachers' teaching communicative rationality: Connotation, mechanisms and strategies. Asian Social Science, 7(3), 117-122.

Shepherd, C. (2000). Competence frameworks - On-line tutors. Institute of IT Training. Retrieved from www.illt.org.ukc-onltutor.htm

Simpson, J. (2005). Conventional flaws in synchronous text-based CMC discourse. Discourse Studies, 7, 337-361.

Thanh, P.T. H. (2011). An investigation of perceptions of Vietnamese teachers and students toward cooperative learning (CL). International Education Studies, 4(1), 1-12. 
ULD Journal of Learning Design

Special issue: The borderless classroom

Wallhaus, R. (2000). E-learning - from institutions to providers, from students to learners. Paper presented at the The "E" is for everything - E-commerce, E-business, and E-learning in Higher Education Conference, San Francisco. CA.

Walters-Cappola, N., Hiltz, R., \& Rotter, N. (2002). Becoming a virtual professor: Pedagogical roles and asynchronous networks. Journal of Management Information Systems, 18(4), 169189.

Woo, S. T. U. (2006). Professors and students ask colleges not to hang up on skype. The Chronicle of Higher Education, 53(16), 28-30.

Copyright @ 2012 Zen Parry and Craig Baird 